\title{
Arranjos familiares de beneficiários do Programa Minha Casa Minha Vida: trajetórias de benefício e percepções de bem-estar social*
}

\author{
Family arrangements of beneficiaries of the Minha Casa \\ Minha Vida Program: benefit's trajectories \\ and perceptions of social welfare
}

Vitor Matheus Oliveira de Menezes

\section{Resumo}

Por meio de uma abordagem qualitativa, neste artigo analisam-se as percepções de beneficiários do Residencial Jardim Cajazeiras, conjunto habitacional do Programa Minha Casa Minha Vida destinado à faixa 1 e localizado em Salvador (BA), sobre a efetividade da política pública. Buscamos problematizar, assim, as dinâmicas dos arranjos familiares dos beneficiários, introduzindo a noção de trajetória de benefício, que diz respeito à compreensão do benefício pelo Programa a partir das trajetórias de vida dos moradores do Residencial, levando em conta o benefício como uma situação social que perpassa o acesso a bens materiais e simbólicos e configurações (e reconfigurações) das distintas esferas de sociabilidade dos atores sociais. Como analisado através de entrevistas, a dimensão dos arranjos familiares na situação de benefício, e sua capacidade em prover bem-estar para os beneficiários, se apresentou como elemento fundamental da experiência de acesso à política pública.

Palavras-chave: Programa Minha Casa Minha Vida; arranjos familiares; processos de vulnerabilidade; pobreza; bem-estar social.

\begin{abstract}
This article analyzes, through a qualitative approach, the perceptions of beneficiaries of Residencial Jardim Cajazeiras (a housing estate of the Minha Casa Minha Vida Program located in the city of Salvador, northeastern Brazil) about the effectiveness of the public policy. Thus, we problematize the dynamics of the beneficiaries' family arrangements, introducing the notion of benefit's trajectory, which concerns the understanding of the benefit as a social situation that pervades the beneficiaries' access to material and symbolic goods and configurations (and reconfigurations) of their different spheres of sociability. The dimension of family arrangements in the situation of benefit, and their capacity to provide welfare to the beneficiaries, proved to be a fundamental element of the experience of access to the public policy.
\end{abstract}

Keywords: Minha Casa Minha Vida Program; Family Arrangements; Processes of Vulnerability; Poverty; Social Welfare. 


\section{Introdução}

O Programa Minha Casa Minha Vida (PMCMV) foi instituído através da Lei n. 11.977, em 7 de julho de 2009, dispondo sobre a "finalidade de criar mecanismos de incentivo à produção e aquisição de novas unidades habitacionais ou requalificação de imóveis urbanos e produção ou reforma de habitações rurais" (Brasil, 2009). Dessa forma, o PMCMV foi estruturado em subprogramas (Programa Nacional de Habitação Urbana, Programa Nacional de Habitação Rural, MCMV-Entidades) e dividido em estratos diferenciados de renda ( 0 a 3 salários mínimos, 4 a 6 salários mínimos e 7 a 10 salários mínimos).

Diversos problemas relativos ao Programa foram abordados pela literatura especializada, assim como sistematizados por Cardoso e Aragão (2013, p. 44):

(i) a falta de articulação do programa com a política urbana; (ii) a ausência de instrumentos para enfrentar a questão fundiária; (iii) os problemas de localização dos novos empreendimentos; (iv) excessivo privilégio concedido ao setor privado; ( $\mathrm{v}$ ) grande escala dos empreendimentos; (vi) a baixa qualidade arquitetônica e construtiva dos empreendimentos; (vii) a descontinuidade do programa em relação ao SNHIS e a perda do controle social sobre a sua implementação; (viii) a desigualdade na distribuição de recursos como fruto do modelo institucional adotado.

Marguti (2013, p. 250), por sua vez, nos apresenta a preocupação com a análise da dimensão dos vínculos sociais dos beneficiários nos conjuntos habitacionais do PMCMV, levando em conta que a alocação em regiões distantes da origem dos habitantes "pressupõe o rompimento dos vínculos sociais e daqueles estabelecidos com o território". Seria importante, segundo a autora, que, na impossibilidade de construção de moradias próximas às habitações originais dos beneficiários, fossem criadas " condições para que as famílias se adaptem o mais rapidamente possível à sua nova posição dentro do espaço urbano, de forma a gerar substancial redistribuição de renda real para essa população" (ibid.). Embora estejamos em concordância com a crítica da autora sobre a construção de habitações distantes dos bairros de origem dos beneficiários, discordamos do elemento analítico que subjaz seu argumento. Defendemos aqui a necessidade de estudos que complexifiquem a dimensão dos vínculos sociais dos beneficiários, para além da "pressuposição" do rompimento, levando em conta uma compreensão científica da dinâmica social dos conjuntos habitacionais. Dessa forma, compreendemos como de fundamental importância a análise dos arranjos familiares dos beneficiários, problematizando as percepções dos interlocutores sobre o bem-estar social no momento de pós-ocupação do Programa. Busca-se analisar, pois, de que forma os beneficiários vivenciam no cotidiano o acesso a recursos materiais e simbólicos, evidenciando os arranjos familiares como dimensão privilegiada de análise de tal processo social.

Argumentamos aqui, em uma perspectiva sociológica, que o benefício deve ser entendido como uma situação social. Para Agier (2011), a situação social tem duas características fundamentais: em primeiro lugar, os atores sociais definem a situação, existe um sentido compartilhado. Em segundo lugar, a situação expressa constrangimentos globais 
e locais aos atores. Relacionam-se, no nosso caso de estudo, significados partilhados pelos beneficiários sobre 0 acesso à política pública e possibilidades e constrangimentos gerados pelo benefício. 0 acesso à moradia termina por servir como novo contexto da vida urbana dos beneficiários, pelo qual os padrões de vínculos sociais produzidos na ordem próxima, ou o não atendimento de expectativas sobre os suportes relacionais, estão relacionados a percepções de efetividade da política pública. 0 vínculo social se apresenta, então, como uma relação interpessoal inserida em uma rede social mais ampla, sendo definido a partir de distintas esferas de sociabilidade. Para este trabalho, concentraremos nossos esforços na dimensão dos arranjos familiares, visto a importância da esfera familiar como suporte cotidiano e para a provisão de bem-estar em contextos de pobreza, principalmente ao levarmos em conta a característica familista do regime de bem-estar brasileiro (Ribeiro, 2010).

De início, defende-se neste artigo a análise da política pública a partir de seus resultados e impactos, por meio da noção de efetividade subjetiva (Figueiredo e Figueiredo, 1986), pondo em destaque as percepções dos beneficiários sobre transformações em suas condições de vida, inquirindo-se o atendimento de expectativas socialmente produzidas e compartilhadas. Segundo Figueiredo e Figueiredo (1986), tal proposta busca levar em conta os desdobramentos materiais, psicológicos e culturais da noção de bem-estar social. Partindo de uma preocupação semeIhante, a Comissão Econômica para América Latina e o Caribe - Cepal (2013) argumenta a necessidade de estudos contemporâneos que problematizem os aspectos subjetivos das políticas públicas e das dimensões de bem-estar. Dessa forma, o significado da noção de bem-estar social está relacionado à satisfação das necessidades básicas dos indivíduos, a partir do atendimento de expectativas socialmente construídas e pela participação na vida em sociedade, tendo em vista o acesso ao consumo, a possibilidade de participação em relações associativas, a inserção estável no mercado de trabalho e a cobertura de riscos sociais, o que nos leva a relacionar o bem-estar à situação de vida de um indivíduo ou de um grupo social (Cepal, 2013). Para Marques, Castello e Bichir (2012), o acesso ao bem-estar social pelas esferas do mercado, da família e do Estado é condicionado pelas configurações das redes sociais interpessoais, relacionadas aos procedimentos das políticas públicas, elementos inter-relacionados no nosso objeto de estudo. Levando em conta a dimensão subjetiva do bem-estar expressa em narrativas, apontamos a centralidade em nosso trabalho de elementos associados aos vínculos sociais dos beneficiários, a partir do relato do acesso a recursos materiais e simbólicos em dada trajetória social.

Recentemente, o Instituto de Pesquisa Econômica Aplicada (Ipea), em parceria com 0 Ministério das Cidades, desenvolveu a "Pesquisa de Satisfação dos Beneficiários do Programa Minha Casa Minha Vida". 0 questionário proposto, trabalhado através da escala de tipo Likert, foi dividido em cinco partes: a funcionalidade da unidade habitacional; o entorno da moradia; a inserção urbana; as despesas com a moradia; e a percepção de bem-estar do beneficiário (Brasil, 2014). Entretanto, mesmo demarcando uma pergunta inicial semelhante ao nosso estudo (percepções dos beneficiários 
sobre o PMCMV), entendemos que este artigo apresenta uma contribuição significativa para os estudos sobre o Programa. Isso porque busca problematizar não somente 0 atendimento de expectativas em relação à política pública, mas também traçar questionamentos sobre a dimensão relacional do espaço urbano, ao analisar as dinâmicas dos arranjos familiares dos beneficiários (tais como a inclusão/exclusão/ reconfiguração dos beneficiários em redes familiares, as trajetórias ocupacionais, a dimensão socioespacial dos arranjos familiares, etc.) como fundamentais para a compreensão das percepções sobre bem-estar social (em nível material e simbólico) e efetividade do PMCMV.

A nossa argumentação converge, pois, para a perspectiva de que as percepções dos beneficiários sobre os resultados do Programa relacionam-se aos processos de vulnerabilidade experienciados no cotidiano. Dessa forma, introduzimos neste trabalho a noção de trajetória de benefício, que diz respeito à compreensão do benefício pela política pública a partir das trajetórias de vida dos beneficiários, sendo o benefício uma situação social que perpassa 0 acesso a bens materiais e simbólicos e configurações (e reconfigurações) das distintas esferas de sociabilidade dos atores sociais. Assim, o benefício pelo Programa deve ser compreendido como uma experiência social, na qual são atribuídos significados a partir da vida social que se desenrola no espaço urbano.

\section{Metodologia}

Partimos de um estudo qualitativo realizado entre 2013 e 2014 em Salvador, capital baiana, no Residencial Jardim Cajazeiras, conjunto habitacional disponibilizado em 31 de outubro de 2011 e destinado à faixa 1 do Programa (população com renda entre 0 e 3 salários mínimos). Os dados apresentados neste artigo fazem parte de um estudo mais amplo, no qual foram entrevistados 10 beneficiários do conjunto habitacional. Para esse trabalho especificamente, foram selecionadas as falas de cinco entrevistados, levando em conta a existência de um padrão unificador do compartilhamento da situação de benefício. Dessa forma, os entrevistados selecionados para este artigo apresentaram a importância (mesmo que por vezes não efetivada) de uma ampla rede de parentesco para o acesso ao bem-estar social. Os outros entrevistados, por sua vez, relataram a centralidade da família nuclear para organização do cotidiano, estruturada com base em uma inserção estável no mercado de trabalho. Optou-se, pois, através de uma preocupação heurística, pela realização de etapas distintas de análise e divulgação científica dos achados, facilitando a exposição e problematização dos discursos. ${ }^{1}$

Assim, são problematizadas entrevistas semiestruturadas ${ }^{2}$ em quantidades variadas com cinco moradores do conjunto habitacional. Os entrevistados foram acessados por meio de mediação do Movimento Sem Teto da Bahia (MSTB), presente no Residencial através de atividades e espaços de sindicância. As entrevistas, então, foram realizadas nos domicílios ou em espaços comunitários do conjunto habitacional. No que diz respeito à análise dos dados, fez-se uso da análise de conteúdo (Bardin, 1977), iniciada através do processo de categorização, no qual foram produzidos dois grupos de categorias: as diferentes percepções, positivas ou negativas, sobre o PMCMV; e a noção de vínculo social, amplamente trabalhada 
pela sociologia, centrando os nossos esforços na dimensão do arranjo familiar. Após essa etapa, realizamos um registro descritivo dos discursos enquadrados nas categorias. Posteriormente, a partir da inferência, foram estabelecidas algumas premissas entre os dois grupos de categorias, partindo de discussões já trabaIhadas na sociologia sobre os processos de vulnerabilidade, a percepção sobre a vida social e a inclusão/exclusão dos atores em redes sociais interpessoais. Por fim, pela interpretação, buscou-se relacionar a efetividade subjetiva da política pública à dimensão dos arranjos familiares dos atores beneficiários. Buscamos compreender, assim, as diferentes atribuições de significado produzidas pelos interlocutores do estudo (Minayo, 2012).

Para dar conta dessa problemática, traremos no próximo tópico contribuições que permitam a intersecção entre nossa proposta de estudo e a dimensão de bem-estar social (entendido não como uma aspiração individual, mas como um produto histórico e sociopolítico), a partir da desigual distribuição de bens e serviços na cidade, a constituição de redes sociais e o regime de bem-estar no caso brasileiro, argumentando a importância do estudo dos arranjos familiares para compreensão do fenômeno em análise.

\section{Espaço urbano, arranjos familiares e bem-estar social}

Para Lefebvre (1991), a cidade seria uma obra de agentes históricos e sociais, representando uma mediação entre a ordem próxima e a ordem distante. Por ordem próxima, o autor entende as relações entre os indivíduos e grupos relativamente amplos (como famílias, vizinhança, corporações, etc.), enquanto a ordem distante é "regida por grandes e poderosas instituições", com destaque para o Estado (Lefebvre, 1991, p. 46). A ordem próxima e a ordem distante representam a produção do urbano a partir de diferentes grupos, em nível macro e micro, definindo uma pluralidade de agências. Tal relação entre ambas as ordens termina por demarcar a cidade como uma mediação, contendo e mantendo a ordem próxima e se sustentando através de uma ordem distante, projetando-a sobre o espaço. No entanto, a ordem próxima não é pré-definida, ela também toma para si o imediato temporal e espacial através das ações cotidianas (Lefebvre, 1991).

Levando em conta os processos de segregação e dispersão dos grupos sociais nas cidades, a partir do fenômeno da "integração desintegrante", Lefebvre (1991, p. 91) problematiza: "diante de quem e para quem é que se estabelece a simultaneidade, a reunião dos conteúdos da vida urbana?". Partindo da perspectiva de que essas possibilidades estão distribuídas desigualmente entre os citadinos, Lefebvre aponta que o direito à cidade seria uma exigência, um "apelo" pelo direito à vida urbana em sua plenitude, o acesso à cidade a partir de seu valor de uso, que garantiria a virtualidade do agir aos seus habitantes. Ou seja, o acesso irrestrito à estrutura urbana que traria em si a virtualidade da ação dos atores na ordem próxima (Lefebvre, 1991). Assim, discutindo sobre o contexto parisiense do pós-segunda guerra, o autor apresenta que a habitação não havia se tornado um serviço público, mas, sim, um apêndice dos direitos do homem expressos na cidade pela economia de mercado. Em verdade, 
mesmo a atuação estatal na produção de moradias não teria revertido as orientações e concepções adotadas pela economia de mercado (ibid.). Com ressalvas de contextualização, podemos apontar que essa discussão está presente nos estudos atuais sobre o PMCMV. Nos conjuntos habitacionais, nos fala Lefebvre (1991, p. 19), haveria a adoção mais funcional da noção de habitat pela burocracia estatal, a partir da soma de coações no cotidiano, não correspondendo à "apropriação pelos grupos e indivíduos das suas condições de existência".

Segundo Santos (2002), o valor do indivíduo dependeria do lugar onde se encontra situado na cidade, tendo em vista o acesso desigual a bens e serviços essenciais. A rede urbana teria significados diferenciados segundo a posição financeira e espacial dos grupos sociais, demarcando dois extremos: de um lado, existem os citadinos que dominam os recursos, podendo desfrutar do trabalho alheio que, transformado em mercadoria, torna-se fluxo. Da mesma forma, o próprio habitante transforma-se em fluxo, deslocando-se pela cidade a partir da ativação da rede de transporte pública ou privada. Em outro extremo, existem os pobres de recursos, "prisioneiros do lugar", inseridos em constrangimentos à apropriação de fluxos externos e pela incapacidade de transformar-se em fluxo através do deslocamento. Como nos diz Santos (2002, p. 140), "para estes, a rede urbana é uma realidade onírica, pertence ao domínio do sonho insatisfeito, embora também seja uma realidade objetiva".

Prosseguindo, podemos afirmar com Lefebvre (1991) que a cidade termina por envolver o habitar, constituindo-se como a forma definidora do local de vida privada. Dessa forma, esta vida urbana tenta voltar as mensagens contra elas mesmas, as ordens, as coações vindas do alto. Tenta apropriar-se do tempo e do espaço frustrando as dominações, desviando-se de seus objetivos, usando de astúcia. Ela intervém também, mais ou menos, ao nível da cidade e do modo de habitar. 0 urbano é assim, mais ou menos, a obra dos citadinos em lugar de se impor a eles como um sistema: como um livro já acabado. (p. 66)

Voltando a Santos (2006), vemos que a rede social deve ser compreendida como social e política, transpondo materialmente uma abstração conceitual e mostrando-se no presente como um suporte corpóreo do cotidiano na relação dos elementos da rede com a vida social (Santos, 2006). No entanto, o autor argumenta que as redes não carregam em si somente a uniformidade, mas também a desigualdade de seu aproveitamento social, no uso diverso que os agentes sociais desempenham através da atuação, controle e regulação. As redes devem ser percebidas como ferramentas de poder e de disputa por diferentes intencionalidades, apresentando não somente a homogeneidade e ordem, mas também o conflito e a desordem (Santos, 2006).

Marques (2007), por sua vez, nos convida a pensar o estudo de redes sociais através de sua inserção no espaço urbano, desenvolvendo a análise de uma ontologia relacional da pobreza, aferindo os efeitos de desagregação e pertencimento das relações socioespaciais. Entendemos, a partir de Marques (2007), a ontologia relacional da pobreza como uma tentativa de compreender a pobreza urbana para além dos atributos dos atores (em análises baseadas na carência de bens e serviços), levando 
em conta os vínculos sociais estabelecidos em determinadas esferas de sociabilidade pela população pobre.

As redes sociais, como nos mostra Agier, são definidas a partir dos critérios de cooperação, ou seja, segundo a natureza da relação social que está na base da existência da rede. Dessa forma, "a hipótese é que há uma relação substancial entre o tipo de laço social, a função e o conteúdo moral da rede" (Agier, 2011, p. 80). É evidente, pois, que as diferentes dimensões de sociabilidade dotam as redes de características específicas, tanto na forma quanto na função dos suportes relacionais. Assim, trazemos para esse trabalho a noção do arranjo familiar como categoria central, o que nos remete à discussão sobre o papel das famílias na provisão de bem-estar e a problematização das relações intrafamiliares.

Ribeiro (2010), baseado na tipologia de Esping-Andersen, aponta que os ativos capazes de atribuir condições materiais e sociais de reprodução objetiva e subjetiva aos seus portadores são acessados através de três esferas distintas: o mercado, o Estado e a família ou comunidade. Para o autor o Brasil, situado em um contexto de capitalismo periférico, realizou um processo inacabado de mercantilização da força de trabalho, de maneira análoga a uma desruralização do país, criando uma massa urbana marginal excluída ou incluída de forma precária nas relações mercantis. Esse processo seria fundado a partir da "combinação das livres forças de mercado e na mobilização das estruturas familiar-comunitárias" (Ribeiro, 2010, p. 222). Dessa forma, para Ribeiro a reprodução social esteve historicamente estabelecida no Brasil através da combinação mercado - família/comunidade. Por isso, o autor designa o sistema de provisão de bem-estar brasileiro como "familístico-mercantil", e a característica de crescente vulnerabilidade do espaço urbano seria, segundo ele, resultado da fragilização de tal modelo (Ribeiro, 2010). Assim, segundo Campos e Teixeira (2010), o modelo latino de regime de bem-estar, incluindo-se aí o Brasil, caracteriza-se pelo elevado grau de desempenho atribuído à família, resultado da presença insuficiente do Estado na esfera do bem-estar social.

Levando em conta o marcado familismo da provisão de bem-estar no caso brasileiro, argumenta-se que a família se apresenta como elemento fundamental para gestão de recursos em situações de escassez. Mas além disso, a família é um elemento-chave para a "proteção e socialização de seus componentes, transmissão do capital cultural, do capital econômico e da propriedade do grupo, bem como das relações de gênero e de solidariedade entre gerações" (Carvalho e Almeida, 2003, p. 109). Assim como Carvalho e Almeida (2003) apontam, no contexto brasileiro e latino-americano, devido às características do mercado de trabalho e desigualdade de acesso aos bens e serviços públicos, a família e os "entornos sociais imediatos" ganham importância para o atendimento de carências de bens materiais, culturais e simbólicos.

Tais bens não são fundamentais apenas para a subsistência, mas também para a criação da identidade individual e grupal e para a "alimentação de uma interioridade". Assim, para pessoas e grupos em situação de vulnerabilidade social, "é a família, sobretudo, que pode transmitir-lhes, entre outros aspectos, um patrimônio de 'defesas internas'" (Carvalho e Almeida, 2003, p. 118). Martins (2006), por sua 
vez, argumenta que a noção de família deve ser complexificada através do uso da noção de "arranjos familiares", expandindo a discussão sobre as relações da família para além dos laços consanguíneos, integrando redes sociais locais e expandindo a noção da família para além do domicílio. Segundo Carvalho e Almeida (2003), por vezes tratada como o núcleo familiar residencial, a família também pode ser compreendida a partir de laços consanguíneos, consensuais e jurídicos, constituindo amplas redes de parentesco.

Sobre a noção de vulnerabilidade social, central neste estudo, Castel (1995) chama atenção para a possibilidade de o conceito de exclusão tratar o fenômeno da pobreza como um estado que se realiza em si mesmo. Em contrapartida, o autor propõe a noção de vulnerabilidade como um processo social, em que estariam relacionadas diferentes zonas de inserção dos distintos grupos na sociedade (ibid.). A maior parte da classe trabalhadora estaria inserida, segundo Castel (1995), na "zona de vulnerabilidade", equilibrando-se entre a zona de integração e zona de exclusão. A precarização do trabalho, a desestruturação dos ciclos vitais e a fragilização dos suportes relacionais demarcam o processo de crescente vulnerabilidade e de passagem para a zona de exclusão. Enquanto o extremo "ótimo" da relação inclusão versus exclusão apresenta o fortalecimento do vínculo social, a zona de exclusão é marcada pela ruptura do vínculo ao trabalho e aos suportes relacionais. Dessa forma, em outros termos, vemos no pensamento de Castel (ibid.) a busca por compreender a pobreza como um processo social que objetiva a problematização das privações dos indivíduos, especialmente as características específicas de sua força de trabalho e o papel do vínculo social para a compreensão da vulnerabilidade.

Marques (2007) aponta, a partir de estudo de redes sociais no contexto de pobreza urbana em São Paulo, a importância da habitação para a estruturação dos vínculos sociais dos pobres. Os diversos suportes relacionais de cunho institucional ou informal (tais como associações comunitárias, religiosas e relações de vizinhança) assumiam no local de moradia a centralidade dos nós da rede social. Em contraste, as redes sociais da população de classe média se encontravam mais espalhadas pelo espaço urbano, estando centralizadas no contexto das relações de trabalho. Assim, ao estarmos tratando do benefício da moradia pela população pobre em Salvador, entendemos a importância de estabelecer a centralidade da habitação para o entendimento dos suportes relacionais e o processo de vulnerabilidade dos moradores. Apresentamos como dimensão fundamental a habitação (e as transformações decorrentes do benefício), mas destacamos, dialogando com Castel (1995), impactos das trajetórias ocupacionais nas expectativas dos suportes relacionais.

Aproximando-nos das análises sobre 0 contexto de Salvador, destacamos a argumentação de Carvalho e Pereira (2008, p. 110), na qual se apresenta que "a urbanização e o desenvolvimento brasileiros vêm se mostrando, historicamente, incapazes de assegurar melhores condições de trabalho e de subsistência para o conjunto da população urbana". A capital baiana foi marcada historicamente por uma urbanização extremamente desigual, culminando na produção de uma cidade demarcada por "cidades" distintas, tendo em vista a alocação desigual de infraestrutura e serviços (Carvalho 
e Pereira, 2008). Acompanhando o padrão centro-periferia típico das metrópoles latino-americanas, a urbanização de Salvador se deu a partir do espraiamento urbano, por meio da expansão horizontal da pobreza com base na autoconstrução de moradias, distanciando-se de centros irradiadores de bens e serviços.

Como nos apresentam Carvalho e Pereira (ibid.), as transformações decorrentes do crescimento demográfico entre os anos 1940 e 1950 foram seguidas de um projeto de modernização excludente entre os anos 1960 e 1970. Tal projeto foi marcado pela construção de grandes obras que acompanharam e anteciparam vetores do crescimento urbano, de maneira análoga à crescente pobreza urbana manifesta na ocupação de terras e autoconstrução de moradias por famílias de baixa renda. Nos anos 1980, um conjunto de intervenções terminaram por configurar de maneira decisiva "um novo padrão de produção do espaço urbano, com a configuração de três vetores bem diferenciados de expansão da cidade: a Orla Marítima norte, o 'Miolo' e o Subúrbio Ferroviário" (Carvalho e Pereira, 2008, p. 85). 0 Residencial Jardim Cajazeiras, objeto de nosso trabalho, encontra-se no segundo vetor, o Miolo da cidade de Salvador, localizado

no centro geográfico do município, [que] começou a ser ocupado pela implantação de conjuntos residenciais para a "classe média baixa" na fase áurea da produção imobiliária através do Sistema Financeiro de Habitação, tendo a sua expansão continuada por loteamentos populares e sucessivas invasões coletivas, com uma disponibilidade de equipamentos e serviços bastante restrita. (Carvalho e Pereira, 2008, p. 86)
Anteriormente ao benefício pelo PMCMV, os beneficiários entrevistados residiam em localidades do Miolo e do Subúrbio Ferroviário, além de ocupações urbanas como na Avenida Gal Costa. Seguindo a terminologia de Carvalho e Pereira (2008), tais localidades estão representadas em sua maioria, em nível demográfico, pela categorização ocupacional da população em "popular" e "popular inferior" (a tipologia completa consiste em superior, média superior, média, média inferior, popular e popular inferior). A categoria popular é entendida como "áreas onde predominam trabalhadores manuais da indústria e comércio, assim como prestadores de serviços com alguma qualificação" (Carvalho e Pereira, ibid., p. 88). Já as classificadas como popular inferior representam uma conjugação dos trabalhadores das áreas populares, como "prestadores de serviços não qualificados, trabalhadores domésticos, ambulantes e biscateiros" (ibid.). Haveria, segundo os autores, uma convergência entre estrutura sócio-ocupacional e apropriação do espaço urbano, e tal apontamento pode ser confirmado pela observação do território de Salvador, onde existe clara conformação entre as categorias ocupacionais e a provisão de infraestrutura urbana.

Tendo em vista esse panorama, destacamos que os beneficiários do Residencial Jardim Cajazeiras expressam um elemento conflituoso na trajetória do benefício pelo PMCMV. Por um lado, a nova moradia é reconhecida como elemento positivo na melhoria da qualidade de vida dos entrevistados. Todos os entrevistados apresentaram essa percepção, sem exceção. No entanto, outra percepção também foi apresentada sem exceções: a baixa qualidade, 
ou inexistência, da infraestrutura urbana na localidade da nova moradia. Apontamos, assim, que a transformação das condições de moradia, através do benefício pela política pública, gerou uma expectativa não atendida de transformações de igual intensidade nos serviços locais, como a proximidade de postos de saúde, escolas, creches e comércio.

Tal problemática, nota-se, é recorrente nos conjuntos habitacionais do PMCMV. Como destaca Shimbo (2010), a valorização seletiva do espaço urbano realizada pelas empreiteiras serve como qualificação das áreas da cidade a partir do público-alvo dos empreendimentos, destacando-se a manifesta periferização dos condomínios destinados à população situada na faixa de 0 a 3 salários mínimos (Cardoso e Aragão, 2013). Soma-se a isso "certo descompasso na resposta dos governos locais e estaduais na instalação de postos de saúde, pronto atendimento, creches e escolas próximos às áreas dos empreendimentos" (Brasil, 2014, p. 83). Dessa forma, o problema apresentado por Carvalho e Pereira (2008), sobre a contiguidade entre categorias ocupacionais e infraestrutura urbana, termina por ser reproduzido na provisão de moradias pelo PMCMV, contexto fundamental para entendermos as entrevistas trabalhadas a seguir.

\section{Arranjos familiares e trajetórias de benefício no Residencial Jardim Cajazeiras, Salvador-BA}

Para iniciarmos a discussão empírica sobre a configuração dos arranjos familiares e a provisão de bem-estar no Residencial Jardim Cajazeiras, estabeleceremos como primeira aproximação dois beneficiários. Os dois beneficiários estão em situação de considerável vulnerabilidade financeira e apresentam opinião semelhante quanto à melhoria das condições de moradia pós-benefício. No entanto, apontam opiniões completamente distintas no que diz respeito à percepção de efetividade da política pública. 0 argumento a ser utilizado é que a diferenciação da efetividade subjetiva pelos dois beneficiários diz respeito às características distintas de configuraçãolreconfiguração dos vínculos sociais e dos suportes relacionais dos beneficiários no momento da pós-ocupação.

A Interlocutora 1, integrante do Movimento Sem Teto da Bahia (MSTB) e atualmente desempregada, residia anteriormente no bairro de Peri Peri, onde também mantinha laços de parentesco. Há dois anos se tornou beneficiária do PMCMV e destaca em sua primeira fala a percepção sobre a dificuldade de manutenção dos laços de parentesco após o benefício:

Los locais onde os condomínios do Programa Minha Casa Minha Vida estão] são locais longe, eles [os moradores] ficam distantes dos seus familiares, pessoas que na falta de um café, na falta de um açúcar, podiam ta trocando. Eu mesma sou exemplo disso. (Interlocutora 1)

A entrevistada se situa, então, em um contexto de ausência de relações de intercâmbios materiais. Tal ausência é evidenciada como consequência direta do Programa, já que a distância entre o local atual de moradia e a residência dos parentes e dos antigos vizinhos não pode ser transposta. Quando questionada sobre a sua situação financeira atual, a entrevistada optou por nos dar uma resposta performativa: 
Vem cá pra eu te mostrar uma coisa la entrevistada leva o entrevistador para a cozinha]. Eu estou desempregada, estou sem dinheiro. Olhe pra minha geladeira. Só tem água, né? [...] Esse feijão aqui foi a colega que me deu. Não tem nada. Essa semana aqui também só tem isso [...] porque o lugar que a gente mora, que a gente já tem uma ancestralidade local, onde os familiares da gente moraram e a gente continua vivendo no local, a gente tem aquela troca, né? [...] Aquela troca que aqui deixa de existir, porque você não tem parente perto. (Interlocutora 1)

Para a entrevistada, a sua alocação no PMCMV resultou na ruptura de vínculos familiares centrados na antiga localidade de moradia. As redes sociais de proteção são percebidas pela interlocutora como redes de "troca", passíveis de serem ativadas em situações de insegurança financeira e alimentar. No entanto, a sua experiência dentro do condomínio não se seguiu a uma reconfiguração de vínculos estabelecidos através de outros espaços sociais, tais como a vizinhança e o associativismo local. Dessa forma, a sua situação de desemprego não pode ser contornada através da ativação de outras esferas da vida social externas ao mercado ou ao Estado. A impossibilidade de manter os laços de parentesco ativos, expressos na explicação "não tem parente perto", evidenciam a dificuldade da entrevistada em se deslocar pelo espaço urbano, ampliando as relações cotidianas para além da localidade da moradia. Isso se daria, segundo ela, através da precariedade do transporte público e da dificuldade do pagamento da tarifa de ônibus, como relatado pela fala "pego um cartão de passe, boto o dedo na frente assim pra não ver, e entro. Se [o cobrador] ver, manda descer".
A dimensão do vínculo e do deslocamento para além da moradia são inter-relacionadas como as duas grandes desvantagens de morar no conjunto habitacional do Programa:

\begin{abstract}
As desvantagens... transporte... o vínculo familiar que você não tem mais, você perde esse vínculo. Os vínculos das amizades antigas... E outra coisa, isso provoca, isso tem provocado, em mim já provocou e provoca muitas vezes até... uma opressão assim... psicológica. A gente se sente oprimido, porque a gente não pode estar perto de quem a gente gosta. (Interlocutora 1)
\end{abstract}

A centralidade das "amizades antigas" aponta que, para a entrevistada, as amizades estavam presentes em um momento anterior ao seu benefício pela política de provisão habitacional. A ruptura do vínculo familiar e das amizades mais próximas, além de impactar nas condições materiais da interlocutora, também apresentaram como resultado uma "opressão psicológica". Assim, as redes de proteção devem ser entendidas para além da troca material, evidenciando a dimensão simbólica do bem-estar e a possibilidade ou não da percepção de pertencimento. Como destacado por Carvalho e Almeida (2003), os entornos sociais imediatos teriam importância fundamental para o atendimento de carências dos moradores das cidades brasileiras. Além disso, a família teria a função da transmissão de um patrimônio de defesas internas, fortalecendo o acesso a bens materiais e simbólicos (ibid.). Nessa entrevista podemos perceber o impacto do isolamento do indivíduo pobre de suportes relacionais, a partir da intensificação da percepção de vulnerabilidade da beneficiária. 
Assim, ao mesmo tempo em que ela relata a dificuldade em participar da vida social do conjunto habitacional, também nos diz que não consegue se deslocar de forma satisfatória no espaço urbano para além da atual moradia. Os vínculos sociais tidos como importantes, presentes na vida da entrevistada antes do benefício, terminaram por ser obstruídos. Vemos aqui o fenômeno da pobreza urbana descrito por Santos (2002), através da impossibilidade da apropriação dos fluxos urbanos, sendo esses mercadorias; e a incapacidade de transformação do citadino em fluxo, a partir do seu deslocamento pela cidade. Isso, aliado à ruptura do vínculo familiar, visto pela beneficiária como esfera central de provisão de bem-estar e segurança financeira, levaram a moradora a entender o benefício pelo Programa como elemento fragilizador em um processo mais amplo de vulnerabilidade social.

No entanto, a sua participação no movimento social é vista como uma atenuante da sensação de insegurança, a partir das relações de troca dentro do movimento e o fato de os integrantes do MSTB relatados terem vindo do mesmo local de moradia da interlocutora, se mostrando como um fragmento da rede social que permaneceu ativo no conjunto habitacional. No entanto, para a entrevistada, esse fragmento não é suficiente para estabelecer a proteção social desempenhada pela família durante o período anterior ao benefício:

Tinha minha prima, tinha minha outra tia Sueli. Tinha meus primos ali perto, que quando eu precisasse podia recorrer a eles. Aqui já é diferente, né? Eu não tenho mais aquela... quem de vez em quando me dá um suporte é Nêgo, é Mira, que é do movimento, que a gente veio de lá pra cá também... entendeu? É uma dificuldade. (Interlocutora 1)

Vemos, dessa forma, que o benefício através da política pública é percebido e relatado pela entrevistada com arrependimento, mesmo com as melhorias reconhecidas pela interlocutora das condições de moradia. Isso porque as expectativas e necessidades de proteção social da beneficiária não foram atendidas, devido ao rompimento de laços sociais familiares centrados no antigo domicílio. Tendo em vista a sobrecarga da proteção social no arranjo familiar, característico do sistema familista de proteção social, a ausência do vínculo familiar acarreta a percepção de insegurança financeira e vulnerabilização.

De maneira contrária, destacamos uma experiência distinta vivenciada pelo Interlocutor 2. Mesmo em situação de instabilidade financeira, apresenta opinião muito diferente da Interlocutora 1. 0 entrevistado é antigo morador de Itacaranha (bairro de Escada), e após um incêndio, no qual perdeu sua moradia, foi alocado no PMCMV. Atualmente o interlocutor é vendedor autônomo, se utilizando da sua casa, que fica no térreo de um dos blocos do Residencial Jardim Cajazeiras, para vender pequenas mercadorias (bombons, pipoca, refrigerantes, etc.). Além de não ter aposentadoria, por problemas de cadastro não conseguiu ter acesso ao Bolsa Família, embora cumpra os critérios de elegibilidade do Programa. Essa situação se apresenta como um contexto de grande insegurança, somando-se à sua idade elevada (62 anos) e ao fato de atualmente morar sozinho. Questionado se passou ou está passando por situação de insegurança financeira, o entrevistado respondeu: 
Sim, porque eu fiz meu Bolsa Família, desde o meu cadastro do Minha Casa Minha Vida e nunca... já recorri na prefeitura, fui no NAD, peguei toda a papelada e inclusive joguei na Coelba e na Embasa, mas o meu Bolsa Família jamais... não sou aposentado e meu trabalho é esse como autônomo, como citei anteriormente. (Interlocutor 2)

Certamente o fato de o beneficiário ser atendido pelo Programa após o incêndio em Escada impacta na percepção do beneficiário sobre os resultados da política pública, tendo em vista a resolução de uma situação emergencial e extrema. Como o entrevistado relata, "era muito lá embaixo [sua qualidade de vida], eu não tinha onde morar, não tinha mesmo, e hoje tenho". No entanto, esse não é o único balizador do discurso do Interlocutor 2. Vejamos alguns elementos que evidenciam como a reconfiguração dos laços sociais do entrevistado impactou na percepção sobre a efetividade da política pública.

Como relata, o beneficiário tem três irmãs em Itacaranha, que se mantiveram no bairro após sua alocação no conjunto habitacional. No entanto, o entrevistado, ao contrário da Interlocutora 1, apresentou uma noção mais fluida de centralização de suas redes sociais a partir da localidade do bairro (em detrimento da noção de "ancestralidade local" relatada pela Interlocutora 1). Por muito tempo morou fora de Salvador, a partir de trabalhos assalariados ou autônomos, se destacando uma longa estadia no interior do Maranhão. Vê-se que a provisão de recursos assume importância no discurso do entrevistado a partir de seu trabalho, mesmo que precário e ausente de amparo na legislação trabalhista (como a aposentadoria).
Após o benefício pelo PMCMV, o Interlocutor 2 passou a morar com uma amiga advinda do antigo bairro, já que ela havia ficado sem casa e ele havia sido atendido primeiro na fila do cadastro. Esse fato marcou profundamente a inserção do entrevistado no condomínio. Ao ser questionado sobre a comparação entre sua vida antes e após o benefício pelo Programa, 0 Interlocutor 2 respondeu:

\begin{abstract}
Rapaz eu continuo lutando aí, correndo atrás de uma aposentadoria aí que nunca sai... mas, por enquanto tá ótimo. Tá ótimo. Inclusive essa pessoa que morou aqui me ajudou muito, entendeu? Continuo com esse trabalho aqui porque ela deixou pra mim, tá? Me deu a maior força, e eu tô aqui, e no dia que puder ajudar ela, ajudarei [...] é uma pessoa que tem um coração de ouro. Inclusive veio de lá, junto comigo, por isso eu segurei aqui dois anos, sem problemas, sem discussões, sem brigas, e tudo combinado, ótimo [...] Faz três semanas que ela se mudou. Tá ótimo. Liga pra mim, eu ligo pra ela, tá beleza.
\end{abstract}

Na primeira parte da fala, o entrevistado leva em conta a sua insegurança financeira, levando-o a realizar grande esforço pessoal, como visto na frase "continuo lutando aí, correndo atrás de uma aposentadoria que nunca sai...". Logo após, a avaliação positiva sobre sua vida atual retoma a sua antiga colega de moradia, que, além de tornar possível o seu novo trabalho como vendedor ambulante no condomínio, esteve presente como uma figura de apoio e ajuda. Além disso, essa pessoa se mostra como uma figura importante de uma antiga rede de vizinhança que, assim como outras pessoas de Itacaranha, se deslocou para o condomínio após o incêndio em Escada. 
A ida de moradores de Itacaranha se mostra como um elemento importante de possibilidade de manutenção dos laços sociais do entrevistado. No entanto, a partir de sua participação na vida cotidiana do condomínio, o morador conseguiu reconfigurar seus vínculos, tendo como centro o local de moradia, garantindo suporte e apoio social.

Muitas [pessoas] vieram de lá de onde eu morava, e através da minha relação com todo mundo fui conhecendo todo mundo. Todos aqui chega, seu Madruga [apelido], pronto é ali. Todos, todos. (Interlocutor 2)

Sobre a possibilidade de recorrer à ajuda financeira por parte de moradores do condomínio, o Interlocutor 2 afirma:

É, por enquanto não precisou de ajuda, mas eu tenho pessoas que já me prometeram que se houver alguma dificuldade recorrer a eles. Inclusive moram no mesmo bloco que eu [...] Conhecemos-nos aqui. Em reuniões, palestras, brincar um pouco, um dominozinho que brincamos ali no quiosque. $E$ assim vamos fazendo amizades. (Interlocutor 2)

Prosseguindo, o entrevistado aponta que tal situação garante uma maior segurança, "com certeza", visto a percepção de redes sociais que podem ser ativadas em caso de maior vulnerabilidade. Fato esse bastante possível, visto a instabilidade de sua renda a partir do trabalho autônomo e a ausência de aposentadoria e cadastro no Bolsa Família. Vemos a partir do Interlocutor 2 que os suportes relacionais mais imediatos podem ser compostos pelos laços não-consanguíneos, através da composição do domicílio para além das relações de parentesco e a proteção social advinda das relações estabelecidas no cotidiano do conjunto habitacional. Os espaços institucionais e informais mostram-se nas falas do entrevistado como a configuração de uma nova rede social, capaz de assumir a responsabilidade pela provisão de bem-estar em casos de maior vulnerabilidade. Por vezes, o sistema de provisão familista integra em seus conceitos a noção de comunidade (Ribeiro, 2010), já que o acesso a bens e serviços por vezes é alcançado por interações na dimensão da vizinhança. Além disso, é possível que a própria família se expanda para além da consanguinidade (Martins, 2006), fenômeno que exigiria mais dados para sua afirmação em nosso caso.

Assim, alguns elementos evidenciam-se ao compararmos os dois atores sociais em análise. Enquanto para a Interlocutora 10 benefício pelo PMCMV significou desfiliação social e ruptura de laços sociais antigos e importantes, ligados ao parentesco e às relações de vizinhança, para o Interlocutor 2 houve a possibilidade de manutenção dos vínculos sociais existentes anteriormente, garantindo proteção social e pertencimento. Vale lembrar que a Interlocutora 1 salienta a importância da presença de integrantes do movimento social no condomínio, um fragmento de rede social que ameniza os efeitos da ruptura de vínculos. No entanto, tal fato se mostra insuficiente para garantia de bem-estar para a beneficiária. Já para o Interlocutor 2, a manutenção de vínculos significou uma moradia temporariamente conjunta e uma possibilidade de trabalho, que se manteve mesmo após a saída da antiga moradora.

Da mesma forma, a possibilidade de reconfiguração de vínculos aponta dimensões diferenciadas nos dois entrevistados. Como 
vimos, a incapacidade de recompor laços sociais e a ruptura com amizades antigas e redes de parentesco provocou na Interlocutora 1 o que ela chama de "opressão psicológica". Por outro lado, é recorrente nas falas do Interlocutor 2 a presença de novos vínculos sociais reelaborados a partir do novo local de moradia, como visto anteriormente, a partir da possibilidade de ativação de uma rede social de apoio em caso de maior insegurança, tendo como centro o bloco onde reside o beneficiário, estabelecido a partir da vida cotidiana no condomínio. Ainda, como segue, é possível perceber nas falas do entrevistado a imagem do condomínio como um local acolhedor, ao contrário das falas da Interlocutora 1, cuja moradia é vista como inserida em um local de desagregação social.

Aqui todos nós somos uma irmandade. Pelo menos comigo né, não sei os demais [...] A relação comigo todo mundo é... você vê as crianças como chega aí ó. "É seu Madruga, é Seu Madruga". E me adoram essas crianças. $E$ me ajudam muito com esses bombons. Graças a Deus. Não tenho outra renda. 0 meu Bolsa Família, nunca. E aqui eu tô levando. E é assim que eu vou levando. Meus bombons, minhas pipoquinhas e meus refrigerantes. (Interlocutor 2)

0 que é central para compreendermos essas discussões é que o benefício pelo Programa, estando inseridos no bojo do benefício o deslocamento espacial da moradia e a reconfiguração de vínculos sociais, se mostra como um processo social. 0 espaço, pois, deve ser compreendido a partir de múltiplas situações, onde diferentes trajetórias de vida e relações interpessoais configuram percepções diferenciadas sobre a vida em sociedade. Assim, a percepção do ator social sobre a política pública não se mostra como um resultado mecânico e estático de sua situação enquanto beneficiário. Ambos os entrevistados relataram significativa melhoria da qualidade da moradia após a alocação no Residencial Jardim Cajazeiras. No entanto, de forma conflituosa, se relacionam a essa dimensão as expectativas quanto aos vínculos sociais mantidos, rompidos e reconfigurados a partir da alocação no conjunto habitacional.

A responsabilização das famílias pela provisão de bem-estar, destacando-se a expansão da noção de família para o papel das redes de vizinhança e os arranjos familiares, tem como resultado a centralidade do vínculo para a segurança financeira e alimentar de seus membros. Além disso, a participação na vida social se relaciona a uma situação de conforto, de atendimento de expectativas e interesses, elementos que estarão inseridos na percepção do beneficiário sobre a política pública. Os impactos do Programa não são entendidos pelos atores pela simples existência de uma moradia melhor, mas também a partir do aspecto relacional da vida urbana, podendo levar a situações de insegurança e "opressão psicológica" ou situações de segurança e ideia da vida em comunidade.

Assim, a percepção sobre os impactos efetivos da política de provisão de moradias está intimamente relacionada à percepção sobre as condições de pobreza e vulnerabilidade dos beneficiários. Passando, pois, para a análise de outras entrevistas, vemos a argumentação da Interlocutora 3 sobre a maior dificuldade em lidar com as contas mensais após o benefício pelo Programa: 
Rapaz, eu não vou mentir a você não, a situação aqui... A dificuldade aumentou, porque gera-se dívidas que você não tinha antes e que hoje você é obrigado a ter, como por exemplo, há uma prestação que você paga do Minha Casa Minha Vida. É pouco, mas já é uma prestação. Ai vem a luz, aí vem a água, aí vem o condomínio. Aí você quer ter uma vida melhor, aí você contrata uma internet... a situação fica mais complicada, mais difícil. (Interlocutora 3)

Quando questionada sobre o repertório utilizado para lidar com a atual dificuldade financeira, a Interlocutora 3 aponta os amigos próximos e familiares como vínculos prioritários de provisão de bem-estar em situações de maior vulnerabilidade. Então, vê-se que as relações informais e interpessoais são colocadas em primeiro plano, ao invés das relações institucionalizadas. Atualmente a beneficiária trabalha como vendedora no próprio condomínio, tendo um ponto de venda em frente ao conjunto habitacional. Seu marido é operário da construção civil e juntos têm dois filhos, e o mais velho trabalha e mora fora do condomínio e a mais nova, com 10 anos, reside junto com o casal. Curiosamente, a Interlocutora 3 aponta que os diferentes vínculos com os familiares residentes fora do conjunto habitacional não foram enfraquecidos, pelo contrário, se fortaleceram após o benefício. Como nos relata a entrevistada, a razão para isso advém do status da moradia atual do PMCMV, em detrimento da antiga moradia sujeita à precariedade e ao estigma da favela:

Você era discriminado, né [na antiga moradia], "ah, mora na favela, mora num barraco", e hoje não, a pessoa que está aqui tem um status de vida melhor do que o que tinha lá no Gal Costa.
Normalmente, quando você passa por algum problema financeiro, a quem você recorre?

Só meus amigos e familiares

Seus familiares atualmente moram aqui ou em outro bairro?

Não, a maioria mora em outros bairros. Eu só tenho uma filha que também faz parte desse projeto. 0 restante de minha família mora tudo por aí por Salvador espalhado.

E você continua mantendo contato com eles?

Continuo. Agora é que eles vêm me visitar. Muitos quando eu morava na favela nem lá iam. (Interlocutora 3)

0 benefício é relatado, dessa forma, através da melhoria da qualidade de vida pelo reconhecimento de status da moradia atual. Utilizando-se de vínculos não institucionalizados para a provisão de bem-estar, a entrevistada relata, para além da melhoria da moradia, a aproximação de familiares após o benefício, movimento inverso ao relatado pela Interlocutora 1. Os suportes relacionais centrados na dimensão da família terminaram por se fortalecer após a alocação da Interlocutora 3 no conjunto habitacional, fenômeno que nos leva a argumentar que o benefício não somente gera constrangimentos para a manutenção dos vínculos sociais (devido à distância), mas também virtualidades geradas pela nova condição social da moradia.

O PMCMV é apontado pela entrevistada como "um projeto bom. Muito bom, muito bem pensado". No entanto, a beneficiária relata a dificuldade encontrada por alguns moradores no que diz respeito às despesas pessoais após o benefício: 
Quando o governo tira aquelas famílias de determinado lugar que eles já estão habituados a morar, é a mesma coisa desse pessoal que mora na orla do subúrbio, pega esse pessoal de lá do subúrbio e joga lá em Simões Filho, eles não vão ficar lá, eles não vão. Muitos deram, porque você pegar uma unidade dessa e dar por 15, 20 mil, pra mim isso não é dinheiro, é dar. Muitos deram porque não tiveram condições de pagar. (Interlocutora 3)

Além disso, a Interlocutora relata a sua percepção de dificuldade do estabelecimento de novos vínculos centrados no conjunto habitacional. Em comparação à sua antiga moradia, na ocupação da Av. Gal Costa, ela relata:

A ocupação que a gente tinha lá na ocupação era mais fraternal, era mais amigo mesmo, 'fulano tá passando dificuldade', e aqui não tem isso não, é cada um por si. Aquela amizade, aquela preocupação que tinha, um morador da ocupação com outro, aqui não existe isso não. Aqui é cada um na sua e a vida continua. (Interlocutora 3)

Assim, a sua permanência no conjunto habitacional representa o sucesso em manter uma fonte de renda, através do ponto de venda no condomínio, e da manutenção dos vínculos sociais anteriores ao benefício. Mesmo com a incapacidade em ativar uma rede social local capaz de suprir com o bem-estar, visto que a esfera familiar e de amizades próximas são prioritariamente procuradas em situações de insegurança financeira, a beneficiária relata o fortalecimento das relações intrafamiliares, tendo em vista a existência da moradia atual como elemento valorativamente positivo. Na percepção da beneficiária, o enfraquecimento dos laços comunitários locais se deu de maneira análoga ao fortalecimento dos vínculos para além da moradia, sendo esses importantes para a provisão de bem-estar.

De maneira semelhante, a Interlocutora 4 realiza uma distinção sobre a possibilidade de ativação da rede de vizinhança pós-benefício e a rede familiar. Quando questionada sobre 0 repertório utilizado para lidar com situações de insegurança financeira, a beneficiária relata:

Eu busco, assim... ao meu redor eu não posso buscar muito, porque é vizinho, pra já não tá aquela coisa de ficar chato pedindo, não busco muito. Mas assim, tem as tias, que moram em Paripe, tem outras tias que moram no Lobato, avó... sempre eu to buscando ajuda deles, para que não venha a faltar as coisas para meus filhos.

E você consegue manter o contato com eles?

Consigo.

[...]

Como é que você acha que é a relação dos moradores aqui dentro?

Não são unidos.

Você acha que era mais unido na antiga moradia ou aqui?

Era mais unido na antiga. Lá cada qual defendia seu cada qual, e ainda eles defendiam a gente. Era um ajudando o outro. (Interlocutora 4)

A possibilidade de ajuda dos familiares se mostra bastante útil no contexto de vida da beneficiária, onde existe "muita [insegurança financeira], muita mesmo". Mesmo não mantendo contato de proximidade com os moradores da sua atual localidade, aponta para a utilização da família como uma rede social para o provimento de bem-estar para os filhos. Atualmente a entrevistada está sem emprego 
fixo, sendo a única provedora de uma casa com duas crianças, sobrevivendo atualmente através do cadastro no Bolsa Família e trabaIhando como diarista e catadora de camarão no Mercado do Peixe. A Interlocutora 4 nos fala que vive uma situação de grande vulnerabilidade e incerteza, tendo como objetivo atual de vida comprar uma guia para trabalhar de ambulante. No entanto, o aumento das despesas com o benefício e a dificuldade de encontrar emprego a impossibilitam de atingir, por ora, seu objetivo.

Quando questionamos o principal ponto positivo do PMCMV, obtemos como resposta a transformação das condições de moradia. Antes residente em Peri Peri, a moradora também já vivenciou com os dois filhos a situação de rua. A casa para ela, por motivos óbvios, representa um elemento constituidor de segurança, qualidade de vida e autoestima. 0 fato de "só estar aqui, nessa casa maravilhosa" já estabelece o apontamento da entrevistada de que o benefício teve um saldo positivo.

No entanto, ao ser questionada sobre 0 principal ponto negativo do Programa, a beneficiária nos responde que é a existência do desemprego. Vemos que na primeira resposta, sobre o elemento positivo, a entrevistada se utiliza de um elemento condizente com as consequências diretas do Programa, estando a moradia incluída como principal objetivo da política pública. No entanto, como vemos, para a evidência sobre a negatividade da política pública, a beneficiária nos traz um elemento central para sua vida social e para a percepção de vulnerabilidade, mas que não está diretamente relacionado às consequências mais corriqueiramente relacionadas ao Programa.
Analisando mais a fundo a questão entendemos, a partir das falas da entrevistada, que a localidade atual da moradia não tem creche próxima ou escola com turno integral, sendo o cuidado com os filhos uma das principais dificuldades para a beneficiária.

O colégio aqui também não tem muita escolha. É lá em Pau da Lima.

É você que leva eles?

Eu levo, às vezes quando eu vou fazer uma faxina, que é 70, 80 reais, eu peço uma pessoa pra levar pra mim, dando o cartão de passagem pra ela e divido aquele dinheiro que eu ganho na diária com a pessoa. Quando eu acho um emprego lá na Pituba, eu não posso, já perdi vários, por falta de uma creche, de um colégio que entre de manhã e pega de tarde, como tem vários, eu não consigo. Então já perdi vários empregos. (Interlocutora 4)

Prosseguindo com a análise, segundo a entrevistada a situação seria muito mais fácil se na atual moradia habitassem familiares que pudessem ajudar no cuidado com os filhos, retirando uma parte da sobrecarga advinda com a ausência de serviços estatais adequados. 0 desemprego, principal ponto negativo do Programa, é uma consequência de dois fenômenos: a) a ausência de serviços de cuidado institucionalizados, que retirem a sobrecarga da família, e principalmente da mulher, no cuidado e provisão de bem-estar para os membros da família; b) e a ausência de redes familiares no atual local de moradia, que conseguissem, na ausência do serviço estatal, arcar com uma parte das responsabilidades com o cuidado, tornando possível para a entrevistada obter emprego com maior estabilidade. A existência 
do trabalho não remunerado do cuidado, e sua sobrecarga advinda com a ausência de serviços estatais (Campos e Teixeira, 2010), termina por impactar negativamente na inclusão da Interlocutora 4 (uma mulher em situação de pobreza constituindo família monoparental) no mercado de trabalho pago, fundamental para o aumento da renda familiar.

É por isso que a Interlocutora 4 ressalta 0 desemprego como principal ponto negativo do Programa. A baixa presença do Estado no sistema familista de provisão de bem-estar acaba gerando uma sobrecarga nos suportes relacionais da família e da comunidade local. Quando esses falham (uma falha já prevista, por impossibilidades objetivas), a entrada na esfera do mercado como espaço de provisão também é obstruída. 0 benefício pela política pública acaba gerando uma percepção bastante conflituosa da entrevistada, onde de um lado vemos melhorias das condições materiais da moradia e o consequente aumento do bem-estar; e de outro o deslocamento de suportes relacionais concomitante à insuficiência dos serviços estatais, impossibilitando o aumento da renda pela esfera do trabalho remunerado.

A partir de dados provenientes da Interlocutora 5, podemos confrontar novos elementos para análise. Segundo a entrevistada, o benefício se deu de maneira análoga ao enfraquecimento da renda familiar:

Tinha tudo no barraco, mas não tinha segurança. Só que lá era um meio de eu ganhar dinheiro, tinha um bar, muito grande, bem feito, eu ganhava dinheiro durante 0 mês que dava para minha despesa. Aqui eu não tenho condição de ganhar nem 50 centavos, porque o condomínio também não ajuda, o governo era pra fazer uns box aí na frente, pra entregar pra quem tinha já o comércio, e isso não foi feito pela prefeitura. (Interlocutora 5)

São colocados em análise pela interlocutora, assim, dois fenômenos. 0 benefício, por um lado, representou a mudança da moradia, vista como uma transformação positiva. No entanto, a fonte de renda estava alicerçada na antiga localidade de habitação, e o benefício não trouxe consigo a provisão pelo Estado de novas condições de trabalho.

E pelo menos eu tô aqui só problema porque eu sou uma pessoa doente, em tratamento [...] Então, pra você ver, lá em Sussuarana era todo mundo amigo, quem tivesse, quem não tivesse comia do mesmo jeito. Aqui não é assim. Aqui o ritmo mudou, vamos ver quem pode mais [...] Na Sussuarana era o contrário, eu dava para os outros. Não tinha pena de dar uma cesta básica, não tinha pena de dar um dinheiro nem de emprestar. E aqui tá tão difícil, porque eu procuro onde conseguir trabalho e não consigo. (Interlocutora 5)

Chama a atenção o fato de que, na entrevista, a beneficiária se reporta ao benefício pela palavra "tragédia". Como evidenciado acima, tal tragédia se daria a partir de alguns elementos articulados, semelhante ao apontado por Castel (1995) sobre o processo de vulnerabilidade social. 0 benefício terminou por enfraquecer, visto a ausência da atuação estatal no que diz respeito à provisão de condições adequadas de trabalho, a fonte de renda da beneficiária. Somado a isso, o seu marido também se encontra desempregado, fato que inviabiliza a provisão domiciliar.

0 antigo local de habitação da beneficiária é apontado como um local, a despeito das 
condições precárias da moradia, de forte interação entre as pessoas. Tais interações serviam como a provisão de bem-estar em situações extremas ("quem tivesse comia, quem não tivesse comia do mesmo jeito"). Já a moradia atual é apontada como um local de individualização ("vamos ver quem pode mais"), onde a entrevistada não está inserida em relações de intercâmbios materiais. Além disso, através da existência de uma fonte de renda com relativa estabilidade, na moradia anterior a Interlocutora 5 assumia uma posição importante como um nó da rede social, sendo provedora de bem-estar para outros membros da localidade. $\mathrm{Na}$ situação atual de benefício, a entrevistada, sem fonte de renda e sem inserção em redes associativas, encontra dificuldades evocadas como uma "tragédia".

Mas além disso, a entrevistada relatou certa capacidade de ativar a família como rede social em situações de extrema vulnerabilidade.

Eu, meu filho, quem me ajuda foi uma família que me criou. São uma família de empresários da Comercial Ramos, então eles praticamente, a maior ajuda, a maior força é deles. Quando eu to precisando de alguma coisa eu ligo, aí 'venha que a gente vai no mercado', se alguém tá doente $e$ eu não tenho um centavo, 'venha que eu vou te arrumar'. (Interlocutora 5)

Vemos aqui o reforço da argumentação de Martins (2006) sobre a necessidade de expandir a família para além dos laços consanguíneos. No entanto, a ativação da rede familiar não resulta em uma situação de segurança para a entrevistada, mas somente a possibilidade de lidar com situações mais adversas. Com base nas falas da beneficiária, a utilização referida do suporte relacional da família não é tão frequente. A percepção de efetividade da política pública pela entrevistada, então, retoma dois fenômenos simultâneos relacionados ao processo de vulnerabilidade. Em primeiro lugar, o benefício significou a perda da fonte de renda da entrevistada, sendo esse o conteúdo mais presente na entrevista. Em segundo lugar, a Interlocutora 5 foi deslocada de uma rede de vizinhança que poderia, em condições mais adversas, servir como fonte de intercâmbios materiais em situações de maior insegurança. 0 seu entendimento sobre a individualização dos seus vizinhos no momento pós-benefício, aliado à insuficiência da ativação da família para além das situações de extrema vulnerabilidade, articula-se com a ineficácia do Estado em prover condições de trabalho, conformando uma percepção extremamente negativa sobre os impactos da política pública em sua vida.

Vimos, com base nesse conjunto de entrevistas, que a inclusão ou exclusão do beneficiário de redes sociais interpessoais resulta em novas configurações da percepção de efetividade do Programa. A existência de redes sociais familiares e/ou de vizinhança se mostrou importante veículo de provisão de bem-estar na existência de insegurança financeira. Devemos, dessa forma, conceber a capacidade ou incapacidade de ativar os nós dessas redes como elementos fundamentais para o entendimento do processo de vulnerabilidade dos atores sociais. 0 benefício, através da reconfiguração territorial e das novas condições de moradia, se mostra como um novo elemento em tal processo. Defendemos aqui que, na produção de subjetividades sobre a efetividade da política pública, ou seja, a percepção do beneficiário sobre os resultados do Programa, o benefício se relaciona com outros elementos da vida social do 
morador. Tal relação, como vimos, é conflituosa, demarcando tal fenômeno como inserido na configuração da pobreza urbana. A percepção da efetividade da política pública também é, de certa forma, a percepção do ator sobre o seu processo de vulnerabilidade.

Destacamos que, como apresentado por Marques (2007), as redes sociais em situação de pobreza encontram centralidade na localidade de moradia. Sejam redes interpessoais informais, ou redes associativas, religiosas e políticas, os atores sociais em situação de pobreza tendem a se relacionar através da dimensão do habitar. 0 benefício pelo PMCMV se mostra, então, como um dado extremamente importante. 0 acesso à política pública termina por gerar uma reconfiguração territorial do beneficiário, a partir do distanciamento espacial entre os vínculos anteriores ao benefício, centrados na antiga moradia, e a atual localidade de habitação. A manutenção desses vínculos e o surgimento de padrões satisfatórios dos suportes relacionais, ou o oposto baseado na incapacidade de manter ou gerar tais redes de suporte, terminam por constituir elementos fundamentais para a compreensão da pobreza e vulnerabilidade do beneficiário.

Como vimos a partir das entrevistas, a vida em sociedade no conjunto habitacional é referida diversas vezes a partir da baixa coesão dos moradores. Essa baixa coesão é apontada a partir de uma comparação com os padrões de relações sociais da antiga moradia. No entanto, como também é possível destacar, a ativação de novos vínculos sociais a partir das relações interpessoais é percebida por alguns beneficiários como o fortalecimento da vida em sociedade. 0 que queremos apresentar aqui é que visivelmente não existe um padrão generalizante a partir do benefício, mas sim trajetórias distintas dos beneficiários que configuram percepções diferenciadas sobre a política pública.

É necessário destacar também que 0 benefício pelo Programa pode apresentar como resultado a produção de novas formas de configuração das redes sociais. Tais redes podem ser distintas do padrão observado por Marques (2007), baseado na centralidade da localidade da moradia para o estabelecimento dos vínculos sociais da população pobre. Como vimos, alguns entrevistados relataram que, de maneira análoga ao enfraquecimento das redes locais, foi possível perceber o fortalecimento ou manutenção de redes sociais de proteção para além do conjunto habitacional. $A$ família como uma rede, centrada não somente a partir do critério da moradia, pode ser ativada em situações de adversidade para além do espaço urbano mais imediato. No entanto, tal possibilidade deve ser contextualizada a partir das virtualidades e constrangimento dos atores, e não ao simples desejo de utilização dos suportes relacionais. Merece destaque também que, mesmo para os entrevistados que relataram a centralidade dos vínculos para além do conjunto habitacional, o benefício representou o fortalecimento da moradia como espaço de organização da vida social e investimento de recursos materiais.

Sintetizando esse ponto, vemos que diferentes trajetórias de benefício, sendo esse entendido como um processo social, configuram distintas percepções sobre as consequências da política pública na vida dos beneficiários. Tentamos aqui escapar de visões deterministas, que estabelecem uma relação direta e apriorística entre a existência de redes sociais e a avaliação positiva ou negativa da política pública. 
O nosso foco, como destacamos, é problematizar como diferentes trajetórias de benefício no momento pós-ocupação terminam por representar tendências de percepção do beneficiário sobre a vida social.

Vale destacar, por fim, que não consideramos profícuo o imaginário neoliberal de centralidade da dimensão da família e/ou comunidade para provisão de bem-estar. Sob o amparo do Banco Mundial, a desresponsabilização do Estado e a instituição da dimensão do mercado como dimensão "justa" de distribuição de bens e serviços, aliado à mobilização das redes comunitárias locais, potencializaram um quadro marcado por "baixos níveis de crescimento econômico; deterioração das condições de trabalho e renda da população; persistência das desigualdades sociais e espaciais; e uma reorientação profunda das políticas sociais" (Carvalho e Almeida, 2003). Mesmo com mudanças importantes no que diz respeito ao fortalecimento do papel do Estado no Brasil, Carvalho (2008) nos aponta que o quadro social das grandes cidades ainda é considerado grave. Assim como defendido por Campos e Teixeira (2010) e Ribeiro (2010), a problematização do viés familista da interação entre Estado/mercado/família mantém-se como elemento fundamental para compreensão da provisão de bem-estar no caso brasileiro.

Quando trazemos para análise a relação entre os vínculos sociais, os processos de vulnerabilidade e a percepção de efetividade da política pública é porque tais elementos, de fato, se relacionam na produção de uma urbanidade. No entanto, a solução dos conflitos percebidos nas falas dos entrevistados não se dará pelo fortalecimento do associativismo local, e nem pela defesa de que o crescimento econômico, por si, incluiria tais indivíduos em nível produtivo e simbólico. Mesmo defendendo que a inter-relação entre os atores se mostra de extrema importância para o entendimento do processo de vulnerabilidade, para nós os resultados fortalecem a necessidade de responsabilização do Estado, e não das famílias.

\section{Considerações finais}

Neste artigo buscamos problematizar as percepções dos moradores do Residencial Jardim Cajazeiras, destinado à faixa de 0 a 3 salários mínimos, sobre o benefício pela política pública. Para isso, negamos a existência de uma relação direta e sem mediações entre as diretrizes da política (e a forma como foram implementadas) e o público-alvo. Como apresentamos detalhadamente através da fala dos entrevistados, a percepção dos beneficiários sobre os resultados da política pública se dá através da relação conflituosa entre diversos elementos constituidores da vida social. Assim, utilizando a noção de efetividade subjetiva e trabalhando a noção de que os beneficiários são atores inseridos em diversas dimensões de sociabilidade das redes sociais, questionamos os impactos dos vínculos sociais para a percepção de efetividade do PMCMV pelos moradores do Residencial Jardim Cajazeiras. Como dimensão específica de sociabilidade, trouxemos para a discussão a categoria de arranjos familiares.

A moradia por si é reconhecida como elemento positivo gerador de maior estabilidade na vida dos beneficiários, tendo em vista a meIhoria das condições estruturais e a valoração simbólica diferenciada entre habitação anterior ao benefício e a moradia pelo Programa. Vale 
destacar que essa avaliação também é situacional, observada na realidade desse conjunto habitacional, sendo possíveis outras avaliações por parte de beneficiários que passaram por processos diferenciados de benefício e pós-ocupação. Para os fins deste trabalho, ganha realce que a moradia pelo PMCMV trouxe consigo o fortalecimento de expectativas dos beneficiários de acesso a bens e serviços, e o não atendimento de expectativas relacionadas às condições de infraestrutura urbana do bairro onde se localiza o conjunto habitacional mostra-se como elemento negativo na avaliação do Programa. No entanto, tais problematizações poderiam se limitar a tratar o beneficiário como atomizado da vida em sociedade, produzindo percepções sobre a política pública baseado em cálculos utilitaristas de custo-benefício. Como contraponto, apresentamos como eixo fundamental do trabalho a visão de que os beneficiários representam trajetórias distintas de benefício, através de características das condições materiais (de renda e de habitação pós-benefício) e de aspectos relacionais da vida urbana. Entender a percepção de efetividade da política pública pelos beneficiários significa, para nós, problematizar tais trajetórias.

Como demonstrado no corpo do trabaIho, analisamos em nossa pesquisa dados que estabelecem a importância dos vínculos sociais para a produção de subjetividades sobre a política pública. Em verdade, a percepção de efetividade da política pública está inter-relacionada à produção de percepções sobre diversas dimensões da vida em sociedade, e tais dimensões conformam distintos processos de vulnerabilidade dos beneficiários. Assumindo a centralidade da categoria dos arranjos familiares, apontamos que os suportes relacionais centrados na família constituem dimensão fundamental da provisão de bem-estar para a população pobre, fenômeno potencializado pela tipificação familista característica do contexto brasileiro.

Assim, de maneira extremamente sintética, a associação do benefício à exclusão do beneficiário em redes sociais de apoio e suporte constituiu uma série plural e diversa de avaliações negativas sobre a política pública, sendo essa vista como um processo contraditório de melhorias materiais da moradia e fragilização dos suportes relacionais centrados na família. Do contrário, quando o benefício pelo Programa está associado à inclusão dos beneficiários em redes de suporte (algumas centradas nas relações institucionais e/ou informais no conjunto habitacional), ou à manutenção de redes existentes anteriores ao benefício, vemos uma tendência a avaliações positivas dos beneficiários sobre os resultados da política pública. Para nós, isso se fez presente porque a percepção sobre os resultados da política relaciona-se à percepção dos beneficiários sobre o processo de vulnerabilidade que eles, de maneiras distintas, vivenciam no cotidiano. Argumentamos, pois, que os arranjos familiares constituem dimensão central de produção de percepções dos beneficiários sobre os resultados da política pública, a partir das características das redes e das trajetórias dos atores (em relação ao mercado de trabalho, ao espaço urbano, etc.).

Argumentamos aqui que os nossos esforços convergiram em uma direção comum. Discutir sobre a percepção dos beneficiários em relação aos resultados de uma política pública de provisão de moradias significa, em nível mais geral, compreender a produção do espaço urbano que vivenciamos em nossas 
cidades. Da mesma forma que o benefício pelo Programa representa a melhoria de condições materiais de moradia, também está associado ao fortalecimento das expectativas dos beneficiários em relação aos serviços e infraestrutura urbana. Além disso, o benefício constitui um novo contexto social onde vão se desenrolar as diferentes dimensões de sociabilidade dos atores beneficiários. Compreender a pobreza urbana perpassa, pois, a tentativa de trazer para a discussão a inter-relação entre condições materiais e dimensões relacionais da vida nas cidades. A trajetória de benefício, contribuição analítica de nosso esforço, se mostra como uma experiência social situacional, provocando transformações na dimensão do habitar dos beneficiários e servindo de contexto (com suas possibilidades e constrangimentos específicos) para as relações sociais dos moradores.

Mas o que significa dizer que o benefício é uma experiência? Como apontado por Brah, 2006, p. 360),

"experiência" é um processo de significação que é a condição mesma para a constituição daquilo a que chamamos "realidade". Donde a necessidade de re-enfatizar uma noção de experiência não como diretriz imediata para a "verdade", mas como uma prática de atribuir sentido, tanto simbólica como narrativamente: como uma luta sobre condições materiais e significado [...] Contra a ideia de um "sujeito da experiência" já plenamente constituído a quem as "experiências acontecem", a experiência é o lugar da formação do sujeito.

A produção de subjetividades sobre a política pública e, assim, sobre a vida em sociedade desenrola-se como uma experiência inserida no processo de vulnerabilidade dos beneficiários. A prática de atribuição de sentidos sobre o benefício, tendo em vista as disputas por condições materiais e de significado referidas por Brah (2006), se dá como constituição do beneficiário como ator social. As distintas configurações dos arranjos familiares após o benefício, e sua capacidade em prover bem-estar para os beneficiários, se apresentaram como elemento fundamental da experiência de acesso à política pública.

Dessa forma, entendemos que a análise das trajetórias de benefício mostrou-se uma possibilidade profícua de estudo sobre o PMCMV, levando em conta a dimensão material e simbólica da sociabilidade urbana e suas interfaces, a partir dos arranjos familiares, com a provisão de bem-estar. A nossa contribuição se apresenta, então, como um estudo sobre a política pública a partir da análise sociológica dos arranjos familiares dos beneficiários, problematizando os distintos processos de vulnerabilidade vivenciados a partir da situação social de benefício.

\section{Vitor Matheus Oliveira de Menezes}

Universidade Federal da Bahia, Faculdade de Filosofia e Ciências Humanas, Programa de Pós-Graduação em Ciências Sociais. Salvador/BA, Brasil vitormatheus_ba@hotmail.com 


\section{Nota}

(*) Parte dos dados trabalhados no artigo foi publicada nos Anais do VI Encontro Nacional de Sociologia e Política.

\section{Referências}

AGIER, M. (2011). Antropologia da Cidade: lugares, situações, movimentos. São Paulo, Terceiro Nome. BARDIN, L. (1977). Análise de Conteúdo. São Paulo, Edições 70.

BRAH, A. (2006). Diferença, Diversidade, Diferenciação. Cadernos Pagu, n. 26, pp. 329-376.

BRASIL (2009). Lei n. 9.887, de 7 de julho. Dispõe sobre o Programa Minha Casa, Minha Vida - PMCMV e a regularização fundiária de assentamentos localizados em áreas urbanas; altera o DecretoLei no 3.365, de 21 de junho de 1941, as Leis nos 4.380, de 21 de agosto de 1964, 6.015, de 31 de dezembro de 1973, 8.036, de 11 de maio de 1990, e 10.257, de 10 de julho de 2001, e a Medida Provisória no 2.197-43, de 24 de agosto de 2001; e dá outras providências. Presidência da Casa Civil, Brasília, DF. Disponível em: http://www.cidades.gov.br/images/stories/ArquivosSNH/ ArquivosPDF/Leis/L11977compilado_2009_07_07.pdf.

(2014). Ministério das Cidades/Secretaria de Assuntos Estratégicos da Presidência da República. Pesquisa de satisfação dos beneficiários do Programa Minha Casa Minha Vida. Brasília, DF: MCIDADES; SNH; SAE-PR; IPEA.

CAMPOS, M. S. e TEIXEIRA, S. M. (2010). Gênero, família e proteção social: as desigualdades fomentadas pela política social. Rev. Katál. Florianópolis, v. 13, n. 1, pp. 20-28.

CARDOSO, A. L.; e ARAGÃO, T. A. (2013). "Do fim do BNH ao Programa Minha Casa Minha Vida: 25 anos da política habitacional no Brasil”. In: CARDOSO, A. L. (org.). O Programa Minha Casa Minha Vida e seus efeitos territoriais. Rio de Janeiro, Letra Capital.

CARVALHO, I. M. M. de (2008). "Trabalho Renda e Pobreza na Região Metropolitana de Salvador". In: CARVALHO, I. M. M. de e PEREIRA, G. C. Como anda Salvador e sua Região Metropolitana. Salvador, Edufba.

CARVALHO, I. M. M. de. e ALMEIDA, P. H. de (2003). Família e Proteção Social. São Paulo em Perspectiva, v. 17, n. 2, pp. 109-122.

CARVALHO, I. M. M. de e PEREIRA, G. C. (2008). "As Cidades de Salvador". In: CARVALHO, I. M. M. de e PEREIRA, G. C. Como anda Salvador e sua Região Metropolitana. Salvador, Edufba.

CASTEL, R. (1995). De la exclusión como estado a la vulnerabilidad como proceso. Justice sociale et inegalités, Esprit, París, 1992; trad.: Archipiélago, n. 21, Barcelona.

CEPAL (2013). Panorama Social da América Latina. Santiago, Chile: Naciones Unidas - Cepal (Coleción Informes Anuales). 
FIGUEIREDO, M. F. e FIGUEIREDO, A. M. C. (1986). Avaliação política e avaliação de políticas: um quadro de referência teórica. São Paulo, Idesp.

LEFEBVRE, H. (1991). O Direito à Cidade. São Paulo, Moraes.

MARGUTI, B. O. (2013). "Conjuntos Habitacionais: estruturação socioespacial e acesso à cidade município de Santo André". In: CARDOSO, A. L. (org.). O Programa Minha Casa Minha Vida e seus efeitos territoriais. Rio de Janeiro, Letra Capital.

MARQUES, E. (2007). Redes sociais, segregação e pobreza em São Paulo. Tese de livre docência. São Paulo.

MARQUES, E.; CASTELLO, G. e BICHIR, R. (2011-2012). Redes Pessoais e vulnerabilidade social em São Paulo e Salvador. Revista USP, Dezembro/Fevereiro, n. 92. pp. 32-45.

MARTINS, P. H. (2006). “Ação pública, redes e arranjos familiares”. In: FONTES, B. e MARTINS, P. H. (orgs.). Redes, práticas associativas e gestão pública. Recife, Editora Universitária da UFPE.

MINAYO, M. C. de S. (2012). Trabalho de campo: contexto de observação, interação e descoberta". In: MINAYO, M. C. de S. (org.). Pesquisa social: teoria, método e criatividade. Petrópolis, Vozes.

RIBEIRO, L. C. de Q. (2010). Desigualdades de oportunidades e segregação residencial: a metropolização da questão social no Brasil. Caderno CRH, v. 23, n. 59.

SANTOS, M. (2002). O espaço do cidadão. São Paulo, Edusp.

(2006). A natureza do espaço: técnica e tempo, razão e emoção. São Paulo, Edusp.

SHIMBO, L. Z. (2010). Habitação Social, Habitação de Mercado: A confluência entre Estado, empresas construtoras e capital financeiro. Tese de Doutorado. São Carlos, Universidade de São Paulo.

Texto recebido em 31/maio/2015

Texto aprovado em 13/dez/2015 